\title{
SLOOF DAN INDENTIFIKASI KEARIFAN LOKAL DIKALANGAN PEKERJA BANGUNAN
}

\author{
Muhammad Zakaria Umar \\ Jurusan Teknik Arsitektur, Fakultas Teknik, Universitas Halu Oleo Jalan H.E.A Mokodompit Kendari \\ Muzakum@yahoo.com
}

Diterima : 13 November 2015

Layak Terbit : 1 Januari 2016

Abstrak

Arsitektur vernakular yaitu arsitektur yang tumbuh dan berkembang dari arsitektur rakyat serta dibangun oleh tukang. Penelitian ini bertujuan untuk menemukenali potensi lokal yang berkaitan dengan pengetahuan tukang bangunan mengenai sloof. Jenis penelitian yang digunakan adalah kualitatif dengan pendekatan deskriptif. Penelitian ini disimpulkan bahwa pengetahuan tukang bangunan dalam membuat sloof yaitu berprinsip kaku tetapi juga lentur guna merespon bencana alam gempa bumi.

Kata kunci; Arsitektur vernakular, tukang bangunan, sloof.

\begin{abstract}
Measurement tools service quality is using Serv Quality Method. In this study, we tried to see different gap between students' perceptions of employee performance with the level of interest/expectations of students to an existing service using five indicators Serv Quality. Aspects studied is, reliability aspects, responsiveness aspect, assurance Aspects, empathy aspects, and the tangibles aspects. SBA research object because they become the frontline in shaping the image of the ministry in Program vocational UI.

The method used in this research is descriptive analysis method with quantitative approach., ie research that describes a data collection on the observations that have been made. This research activity is a continuation of research since the first semester of 2014/2015 to the first semester of 2015/2016. The population in this study is that students of Administration UI vocational program. Based on the results of this study concluded that there is still a big gap to the five dimensions of Quality Serv.
\end{abstract}

Keyword; Serv Quality, Public Service, Importance-Performance Matrix

\section{PENDAHULUAN}

Arsitektur vernakular di Indonesia terdiri dari karya-karya bangunan tradisional yang hadir dalam beragam bentuk lokal dari masingmasing daerah yang merupakan kekayaan arsitektur Indonesia yang patut dilestarikan (Pramitasari dan Iyati, 2011). Bangunan vernakular merupakan bangunan yang mempunyai keunikan tersendiri. Keunikan bangunan vernakular adalah tahan terhadap lingkungan alamnya, sehingga bangunan vernakular tetap eksis hingga sekarang. Untuk daerah gempa, bangunan vernakular juga telah melakukan penyesuaian terhadap bencana alam gempa bumi yang ada di lingkungannya. Hal ini terbukti bahwa bangunan vernakular di daerah gempa masih eksis hingga sekarang walaupun telah terkena gempa beberapa kali (Triyadi, dkk. 2009). Arsitektur vernakular adalah arsitektur tanpa 
arsitek. Seperti yang diungkap Bernard Rudofdky bahwa arsitektur vernakular dibuat oleh orang-orang biasa. Berlawanan dengan arsitektur yang dirancang oleh seorang arsitek yang lahir melalui proses pendidikan formal, pengetahuan mengenai bangunan pada arsitektur vernakular hanyalah muncul dari sang perancang otodidak yang diperoleh dan disalurkan melalui tradisi lokal semata dan biasanya berdasarkan trial and error yang diturunkan dari generasi ke generasi (Suharjanto, 2011). Arsitektur vernakular yaitu arsitektur yang tumbuh dan berkembang dari arsitektur rakyat serta dibangun oleh tukang yang berdasarkan pengalaman, serta merupakan jawaban atas setting lingkungan tempat bangunan tersebut berada dan selalu membuka untuk terjadinya transformasi (Turan, 1990). Keangkuhan dan keegoisan akademis seorang arsitek terdidik yang sering dianggap moderen dan tidak mau berdialog dengan tukang bangunan akan membuat perkembangan arsitektur mandeg. Penelitian ini bertujuan untuk menemukenali potensi lokal yang berkaitan dengan pengetahuan tukang bangunan mengenai sloof.

\section{KAJIAN PUSTAKA}

\section{Gempa dan Bangunan Vernakular}

Sistem dan struktur bangunan merupakan sistem struktur bangunan yang terintegrasi dan solid. Konfigurasi kolom, rangka dinding bangunan, sistem rangka lantai, rangka langit-langit, dan rangka atap membentuk satu kesatuan yang cukup kaku tetapi masih dapat bergerak apabila terjadi goncangan gempa dan tidak akan terlepas satu sama lain atau tetap utuh (Triyadi, dkk., 2009).Untuk menghasilkan bentuk bangunan yang tahan gempa, perlu dipikirkan bentuk konfigurasi bangunannya. Bentuk konfigurasi struktur bangunan yang cocok untuk menahan gaya lateral dinamik gempa, sebagai berikut; 1). Kekakuan antar tingkat bangunan seragam atau mendekati seragam; 2). Sistem sambungan benar-benar rigid dan kaku; 3). Struktur bangunan harus lengkap yaitu ada sloof, kolom dan ring balk dengan ikatan sambungan yang kaku dan homogen (Purwanto dan Gayatri, 2007).

Material yang digunakan pada bangunan vernakular di Jawa Barat bagian Selatan dalam merespon gempa ditunjukkan dengan: 1) struktur bangunan yang terdiri dari kolom, balok lantai, balok ring, dan lainlain, tersusun menjadi konfigurasi struktur rangka utama, ditambah rangka untuk menempelkan dinding yang sekaligus menyatu dengan struktur utama yang turut menyumbangkan kekakuan secara keseluruhan. Hal ini menyebabkan konfigurasi bangunan secara keseluruhan menjadi struktur box. Struktur box tersebut adalah salah satu struktur yang elastis, ductile terhadap gempa, 2) pondasi bangunan yang berupa umpak batu ternyata sangat sesuai untuk bangunan yang mempunyai rangka bangunan yang solid dan kaku, bila terjadi gempa bangunan tetap utuh hanya bergeser posisinya, 3) seluruh material struktur utama adalah menggunakan kayu, termasuk dalam struktur bangunan ringan yang mempunyai sifat elastis dan liat (Harapan dan Triyadi, 2008). 
Struktur kayu rumah panggung di wilayah Sumatra Barat telah terbukti tahan terhadap pembusukan dan serangan rayap. Struktur panggung juga lebih tahan terhadap getaran akibat gempa bumi. Getaran dari gempa bumi yang diterima struktur balok dan kolom akan disalurkan ke pondasi batu (umpak) tanpa merusak. Sambungan antara kolom kayu dan pondasi batu (umpak) ini bersifat fleksibel, kolom tidak ditanam di dalam pondasi, tetapi hanya ditumpangkan begitu saja. Saat terjadi gempa, sambungan kolom dan pondasi tidak akan patah, tapi hanya bergeser (Hartatik, dkk, 2012).

Berdasarkan uraian di atas dapat disimpulkan bahwa konsep bangunan vernakular dalam berstruktur adalah kaku tetapi juga lentur guna merespon bencana alam gempa bumi.

\section{Sloof}

Sloof adalah suatu elemen struktural yang mampu menahan beban terutama dengan menolak membungkuk. Gaya membungkuk diinduksi ke materi balok sebagai hasil dari beban eksternal, beratnya sendiri, span dan reaksi eksternal untuk beban ini disebut momen lentur. Sloof merupakan bagian konstruksi yang berfungsi menyalurkan beban dinding ke pondasi. Pada proyek perumahan biasanya menggunakan sloof dan ringbalk berdimensi $20 / 30 \mathrm{~cm}$ dan 15/20 cm (Wijaya, dkk., Tanpa Tahun). Sloof adalah struktur dari bangunan yang terletak diatas fondasi, berfungsi untuk meratakan beban yang diterima oleh fondasi, juga berpungsi sebagi pengunci dinding agar apabila terjadi pergerakan pada tanah, dinding tidak roboh. Sehingga sloof sangat berperan sekali terhadap kekuatan dari bangunan, bahan yang digunakan adalah beton dengan campuran 1 semen : 2 Pasir : 3 split (koral). Dimensi sloof yang sering digunakan pada bangunan rumah tinggal lantai satu, lebar 15 $\mathrm{cm}$, tinggi $20 \mathrm{~cm}$, besi beton tulangan utama menggunakan 4 buah diameter $10 \mathrm{~mm}(4 \mathrm{~d} 10$ ) sedangkan untuk begel menggunakan diameter $8 \mathrm{~mm}$ berjarak $15 \mathrm{~cm}(\mathrm{~d} 8-15)$. Untuk rumah lantai dua, dimensi sloof yang sering digunakan adalah, lebar $20 \mathrm{~cm}$ tinggi30 $\mathrm{cm}$, besi beton utama $6 \mathrm{~d} 12 \mathrm{~mm}$, begel $\mathrm{d} 8-10$ cm (Anonim, 2011).

Untuk rumah tinggal tembokan sederhana, kunci ketahanan gempa adalah pemakaian balok pondasi (sloof), kolom praktis dan ring balok yang dibuat dari beton bertulang dan disatukan dengan pasangan batanya (Sukamta, 2006). Pondasi tapak dan sloof adalah komponen yang wajib terangkai baik dan harus stabil (Raharjo, dkk. 2013). Rangka bangunan yang terdiri dari kolom, balok sloof dan balok ring semuanya terbuat dari beton bertulang yang saling berhubungan sehingga membentuk konstruksi ruang. Konstruksi ruang ini mempunyai momen inersia yang besar sehingga lebih kuat menahan momen guling akibat adanya gaya horisontal yang ditimbulkan oleh gempa. Sementara gaya vertikal akibat berat sendiri bangunan yang sebagian besar terbuat dari kayu dan seng relatif ringan sehingga cukup kuat ditahan oleh rangka bangunan yang relatif tidak berdimensi besar (Setiawan, 2007). Dengan pembuatan sampel kolom dan balok atas yang dipasang sesuai yang direncanakan dapat 
disimpulkan struktur tersebut stabil dan apabila terjadi penurunan sebesar $2 \mathrm{~cm}$ atau $1 / 100 \times \mathrm{L}$ sloof $(\mathrm{L}$ sloof $=200 \mathrm{~cm})$ maka struktur masih stabil dan sambungansambungan masih utuh. Apabila terjadi penurunan $4 \mathrm{~cm}$ atau $1 / 50 \times \mathrm{L}$ sloof ( L sloof $=200 \mathrm{~cm}$ ) maka terjadi keretakan pada sloof dan pergoyangan pada sambungan kolom pedestal dengan kolom. Penurunan tidak boleh sampai $1 / 50 \times \mathrm{L}$ sloof dimana pada kondisi ini struktur menjadi tidak stabil (Suwono, dkk. Tanpa Tahun).

Berdasarkan uraian di atas dapat disimpulkan bahwa sloof dalam pembuatannya berprinsip kaku tetapi juga lentur, sloof dan pondasi merupakan komponen yang wajib terangkai, dan penurunan sloof dan pondasi yang diizinkan adalah 1/50 x L sloof.

\section{Pengetahuan Tukang Bangunan}

Program Pelatihan Kepada Tukang

Lokal Dalam Rekonstruksi Rumah Pasca Gempa Pada Nagari-Nagari Di Kabupaten Pasaman (Pembangunan Rumah Yang Sesuai Dengan Persyaratan Pokok Rumah Aman Gempa) sebagai berikut: 1). Sebagian besar mendapatkan ilmu pertukangan secara turun temurun dan tidak mempunyai dasar ilmu di bidang Rekayasa Struktur; 2). Tukang lokal sebagai ujung tombak pembangunan perumahan di masyarakat, memang sudah seharusnya mendapatkan perhatian lebih karena di tangan merekalah ditentukan kekuatan struktur yang didirikan terutama membangun rumah yang aman terhadap gempa; dan 3). Pelatihan ini bermanfaat bagi tukang-tukang lokal untuk serta memperbaiki rumah yang rusak akibat gempa, karena selama ini rumah yang rusak tersebut langsung dirobohkan saja tanpa dicarikan solusi perbaikannya yang lebih hemat dan cepat (Yustisia, dkk., 2014). Peningkatan keahlian tukang dan buruh bangunan dalam membangun rumah sederhana aman gempa bumi di Kota Palu sebagai berikut: 1). Belum tersosialisasinya tata cara membangun rumah sederhana yang aman gempa di kalangan tukang dan buruh bangunan di kota Palu; 2). Tidak seragamnya keahlian tukang dan buruh bangunan di kota Palu dalam pelaksanaan proyek bangunan; 3). Rendahnya daya saing tukang dan buruh bangunan di kota Palu dalam memperoleh proyek bangunan di kota Palu, jika dibandingkan dengan tukang dan buruh bangunan dari luar provinsi Sulawesi Tengah; 4). Kelompok tukang dan buruh bangunan menganggap bahwa bangunan rumah sederhana tidak memerlukan pendetailan struktur yang baik dan dalam pelaksanaannya cukup mengikuti perintah dari pemilik dan pelaksana proyek; 5). Menularkan pengetahuan tentang tata cara membangun rumah sederhana aman gempa kepada kelompok tukang bangunan lainnya (Luthfiah, dkk., 2013).

Berdasarkan uraian di atas dapat disimpulkan bahwa pengetahuan tukang bangunan perlu ditingkatkan karena tukang sebagai ujung tombak pembangunan perumahan di masyarakat.

\section{METODE PENELITIAN}

Penelitian ini dilakukan di Kota Kendari Provinsi Sulawesi Tenggara Indonesia. Jenis penelitian yang digunakan adalah kualitatif 
dengan pendekatan deskriptif terhadap tukang bangunan dalam membuat sloof. Obyek arsitektural yang dipilih adalah sloof rumah berlantai satu dan sloof rumah berlantai dua. Kriteria sloof yang dipilih adalah sloof sedang dalam proses pengerjaan dan sloof yang telah selesai proses pengerjaannya terhadap kekakuan dan kelenturan. Metode pengumpulan data dilakukan dengan cara observasi terhadap sloof dan diskusi mendalam terhadap tukang bangunan. Data dianalisis dengan cara tabulasi data dalam bentuk matriks kemudian dianalisis dengan teknik triangulasi, isi, dan intrepetasi.

\section{HASIL}

Pengetahuan tukang bangunan mengenai pembuatan sloof adalah berprinsip kaku tetapi juga lentur, ada di tabel (1). Prinsip-prinsip kaku ada di kategori sloof sebagai berikut: pengertian sloof, fungsi sloof, rumus dimensi sloof, campuran sloof, hubungan sloof dengan pondasi, sloof lebih tinggi daripada pondasi, letak sloof di atas pondasi, dan rabat lantai di bawah sloof. Prinsip-prinsip lentur ada di kategori sloof sebagai berikut: letak besi tulangan sloof terhadap besi tulangan kolom dan ringbalk, dimensi besi tulangan sloof untuk rumah berlantai 1 dan 2 , pengertian besi behel, letak besi behel, fungsi tekukkan pada besi behel, dimensi besi behel dan ukuran besi tulangannya, jarak ukuran antar besi behel pada sloof, fungsi angkur pada sloof, bentuk besi behel segitiga, dan urutan mencampur di sloof.

Tabel 1. Pengetahuan Tukang Bangunan Mengenai Sloof (Sumber: Hasil analisis, 2016)

\begin{tabular}{|c|c|c|c|c|c|}
\hline \multirow[t]{2}{*}{ No. } & \multirow[t]{2}{*}{ Kategori Sloof } & \multicolumn{2}{|c|}{ Tukang Bangunan } & \multicolumn{2}{|c|}{ Prinsip-prinsip } \\
\hline & & Tukang Bangunan 1 & Tukang Bangunan 2 & Kaku & Lentur \\
\hline 1. & Pengertian sloof & Tulangnya pondasi. & $\begin{array}{l}\text { Tempat menempelnya pasangan } \\
\text { batu merah. }\end{array}$ & Kaku & \\
\hline 2. & Fungsi sloof & Tempat berdirinya dinding. & $\begin{array}{l}\text { Tempat menempelnya pasangan } \\
\text { batu merah. }\end{array}$ & Kaku & \\
\hline 3. & Rumus dimensi sloof & Tidak ada rumusnya. & Tidak ada rumusnya. & Kaku & \\
\hline 4. & Campuran sloof & $1: 3: 2$ & $1: 2: 3$ & Kaku & \\
\hline 5. & $\begin{array}{l}\text { Hubungan sloef dengan } \\
\text { pondasi }\end{array}$ & Satu paket. & Satu paket. & & \\
\hline 6. & $\begin{array}{l}\text { Sloof lebih tinggi } \\
\text { daripada pondasi }\end{array}$ & Bila diperlukan. & Tidak ekonomis. & Kaku & \\
\hline 7. & $\begin{array}{l}\text { Letak sloof di atas } \\
\text { pondasi. }\end{array}$ & Dengan cara dicor. & Dengan cara dicor. & Kaku & \\
\hline 8. & $\begin{array}{l}\text { Posisi besi tulangan } \\
\text { sloof terhadap besi } \\
\text { tulangan kolom dan } \\
\text { ringbalk }\end{array}$ & $\begin{array}{l}\text { Besi tulangan kolom yang } \\
\text { masuk ke dalam besi tulangan } \\
\text { sloof dan ringbalk. }\end{array}$ & $\begin{array}{l}\text { Besi tulangan kolom masuk ke } \\
\text { dalam besi tulangan sloof. }\end{array}$ & & Lentur \\
\hline 9. & $\begin{array}{l}\text { Dimensi besi tulangan } \\
\text { sloof untuk rumah } \\
\text { berlantai } 1\end{array}$ & Besi tulangan sloof 8." & $\begin{array}{l}\text { Besi behel sloof } 8 \text { " dan tulangan } \\
\text { besi sloof } 12 . "\end{array}$ & & Lentur \\
\hline 10. & $\begin{array}{l}\text { Dimensi besi tulangan } \\
\text { sloof untuk rumah } \\
\text { berlantai } 2\end{array}$ & Besi tulangan sloof $14 . "$ & $\begin{array}{l}\text { Besi behel sloof } 8 \text { " dan tulangan } \\
\text { besi } 12 . "\end{array}$ & & Lentur \\
\hline 11. & Pengertian besi behel & Besi yang sudah terbentuk. & Cincin pengikat tulangan besi. & & Lentur \\
\hline 12. & Letak besi behel & $\begin{array}{l}\text { Behel ada di sloof, kolom, dan } \\
\text { ringbalk. }\end{array}$ & $\begin{array}{l}\text { Behel ada di sloof, kolom, ringbalk, } \\
\text { dan balok latei. }\end{array}$ & & Lentur \\
\hline 13. & $\begin{array}{l}\text { Fungsi tekukkan pada } \\
\text { besi behel }\end{array}$ & Agar tulangan lentur. & $\begin{array}{l}\text { Agar tulangan pada besi tidak } \\
\text { mudah terlepas. }\end{array}$ & & Lentur \\
\hline 14. & Dimensi besi behel dan & Dimensi tulangan besi besinya & Dimensi tulangan besi perlu lebih & & Lentur \\
\hline
\end{tabular}




\begin{tabular}{|c|c|c|}
\hline & ukuran besi tulangannya & $\begin{array}{l}\text { perlu lebih besar daripada } \\
\text { behel. }\end{array}$ \\
\hline 15. & $\begin{array}{l}\text { Jarak ukuran antar besi } \\
\text { behel pada sloof }\end{array}$ & $\begin{array}{l}\text { Semakin dekat jaraknya } \\
\text { semakin kuat kekuatan } \\
\text { betonnya. }\end{array}$ \\
\hline 16. & Fungsi angkur pada sloof & $\begin{array}{l}\text { Agar besi angkur tidak mudah } \\
\text { lepas }\end{array}$ \\
\hline 17. & $\begin{array}{l}\text { Bentuk besi behel } \\
\text { segitiga }\end{array}$ & Kekuatan kurang. \\
\hline 18. & $\begin{array}{l}\text { Urutan campuran beton } \\
\text { untuk sloof }\end{array}$ & $\begin{array}{l}3 \text { ember kerikil, } 1 \text { ember } \\
\text { semen, dan } 2 \text { ember pasir. }\end{array}$ \\
\hline 19. & $\begin{array}{l}\text { Rabat lantai di bawah } \\
\text { sloof }\end{array}$ & Tidak kokoh. \\
\hline
\end{tabular}

\section{PEMBAHASAN}

\section{Menemukenali Potensi Lokal Pengetahuan}

\section{Tukang Bangunan Mengenai Sloof}

\section{Prinsip-prinsip Kaku di Sloof}

Struktur kaku adalah bagian struktur yang bentuknya tidak berubah akibat dari gaya dan beban atau beban yang berubah (Tangaro, dkk., 2005). Komponen struktur beton bertulang yang mengalami lentur harus direncanakan agar mempunyai kekakuan yang cukup untuk membatasi lendutan (Soehardjono, dkk., 2016). Suatu struktur harus memiliki kekakuan yang cukup sehingga pergerakkannya dapat dibatasi. Kekakuan bahan itu sendiri dipengaruhi oleh modulus elastisitas bahan dan ukuran elemen tersebut. Modulus elastisitas berbanding lurus dengan kekuatan bahan, maka semakin kuat bahan maka bahan tersebut juga semakin kaku. Namun bahan yang terlalu kaku bisa menjadi getas (Core, 2012). Jadi kekakuan adalah kemampuan struktur agar tidak melendut (berubah) yang dihasilkan dari sintesis kelenturan yang pergerakannya dibatasi dan berbanding lurus dengan kekuatan bahan. Sloof adalah tulangnya pondasi, maksudnya menahan dan membantu pondasi dari beban di atasnya. Sloof adalah tempat menempelnya pasangan batu merah

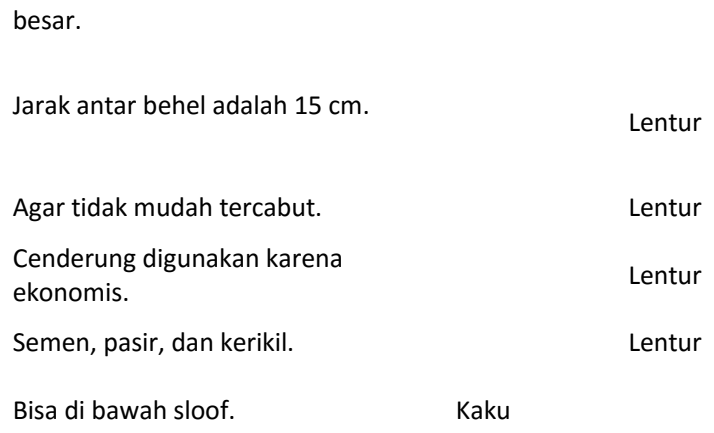

atau batako. Fungsi sloof adalah sebagai tempat berdirinya dinding atau tempat menempelnya pasangan batu merah agar batu merah tidak mudah retak atau patah, ada di gambar (1). Rumus dimensi sloof adalah tidak ada rumusnya. Ukuran dimensi behel sloof untuk rumah berlantai satu adalah 8/12 dan setelah diberi cor menjadi 10/15. Tinggi sloof perlu disesuaikan dengan tinggi peil lantai yang diinginkan dan lebar batu merah atau batako. Semakin tinggi sloofnya, kekuatan sloof juga semakin kuat. Proses pembuatan sloof disesuaikan dengan kebiasaan para tukang, ketebalan batu merah, jumlah tingkat lantai, keinginan penghuni rumah, dan dimensi kolom bangunan. Ukuran dimensi sloof untuk bangunan bertingkat adalah berukuran besar karena disesuaikan dengan pelat lantai betonnya. Sloof yang baik disesuaikan dengan keadaan campuran cornya. Perbandingan campuran cor untuk sloof adalah 1:3:2, artinya 1 ember semen: 3 ember kerikil: 2 ember pasir atau bisa juga dengan perbandingan 1:2:3. Campuran beton tersebut bisa juga langsung 4 pasir kasar:1 semen tanpa kerikil. Ketebalan campuran cornya adalah $2,5 \mathrm{~cm}$. 


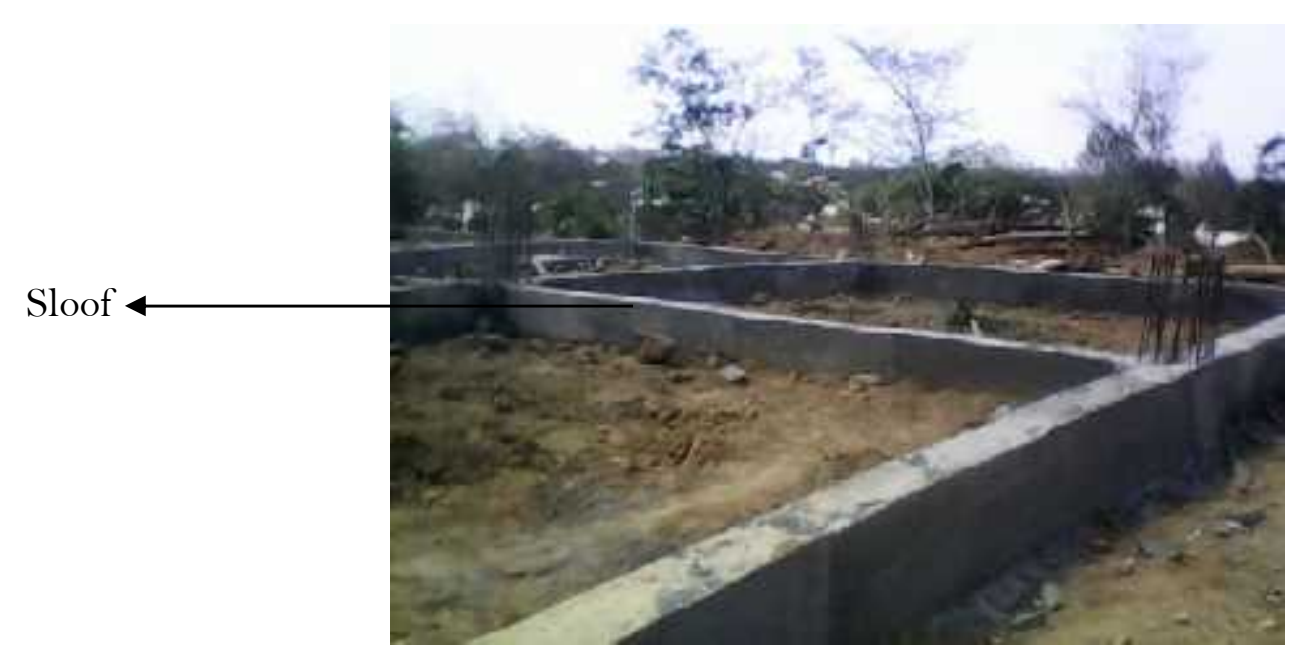

Gambar 1. Sloof pada bangunan Sekolah Internasional di THR Kendari (Sumber: Hasil dokumentasi pribadi, 2015)

Sloof dan pondasi adalah satu paket. Satu paket artinya sloof dan pondasi tidak bisa dipisahkan, karena rumah mempunyai beban yang berat (tulangan besi, beton, baja, kayu, dan sebagainya). Sloof dan pondasi berfungsi untuk menahan beban dinding. Apabila sloof patah maka ada pondasi yang menopang dinding. Pondasi juga berfungsi untuk menahan besi sloof agar tidak mudah berkarat, ada gambar (2). Kedalaman angkur yang di tanam di dalam pondasi adalah $1 / 2$ tinggi pondasi. Plesteran mortar untuk pondasi bisa dilakukan atau tidak bisa dilakukan berdasarkan jarak batu dan kekuatan pondasi. Berdasarkan jarak batu yaitu apabila jarak batu saling berdekatan tidak perlu diisi dengan mortar. Apabila jarak batu tidak berdekatan maka batu perlu diisi dengan mortar. Berdasarkan kekuatan yaitu apabila tidak memakai mortar maka kekuatan pondasi tidak ada. Batu gunung yang disusun perlu memakai mortar sebagai perekat agar lengket satu sama lainnya. Perbandingan mortar untuk pondasi adalah 1:3; 1:4; dan 1:5. Plesteran mortar yang paling baik perbandingannya adalah 1:4 karena mudah kering, pondasi kokoh, dan pondasi tidak mudah retak atau patah. Mortar dengan perbandingan 1:1 dan 1:2 selain tidak efisien juga dapat membuat pondasi mudah patah. Apabila bentuk batu gunungnya besar maka ketebalan campurannya juga tebal yaitu $3 \mathrm{~cm}$.

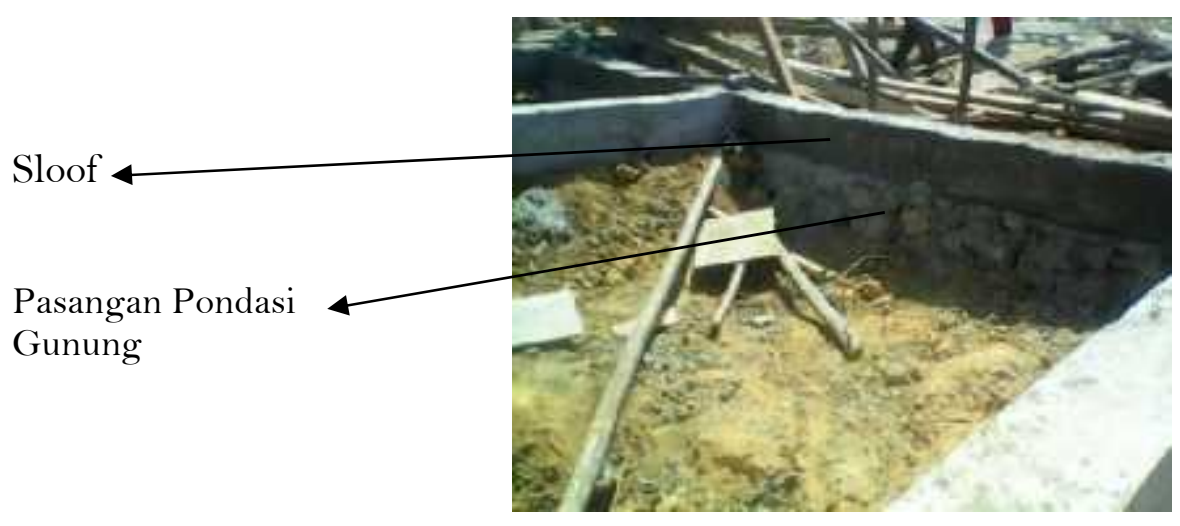

Gambar 2. Sloof dan pondasi adalah satu paket di Sekolah Internasional THR Kendari (Sumber: Hasil dokumentasi pribadi, 2015). 
Sloof dan pondasi saling menempel karena campuran cor (ada bahan semennya) dan besi tulangan yang diikat dengan behel kemudian dibungkus dengan campuran. Jarak ukuran antar behel adalah 5-20 cm, dengan jarak tersebut sloof sudah kokoh. Apabila jarak antar behel adalah $5 \mathrm{~cm}$ maka penggunaan besi behel menjadi tidak efisien. Ukuran jarak behel paling pendek adalah 15 $\mathrm{cm}$ dan paling panjang $20 \mathrm{~cm}$. Sloof lebih tinggi daripada pondasi bila diperlukan. Alasan sloof bisa lebih tinggi daripada pasangan batu gunung karena sloof sebagai tempat dudukan batu merah tidak disesuaikan dengan tingginya pondasi. Alasan sloof tidak bisa lebih tinggi daripada pasangan batu gunung karena tidak ekonomis. Rabat lantai di bawah sloof tidak kokoh. Perletakan rabat lantai tidak perlu di bawah sloof karena rabat lantai tidak ada penyangganya. Rabat lantai di bawah sloof bisa ditempatkan apabila tulangan besi sloof dikeluarkan dari selimut cor agar saling mengkait dengan rabat lantai. Rabat lantai yang baik yaitu perlu ditempatkan di atas sloof agar saling menempel di dinding. Rabat lantai bisa ditempatkan jauh di atas sloof tetapi jarak ketinggian dinding berkurang.

\section{Prinsip-prinsip Lentur di Sloof}

Kelenturan adalah kemampuan untuk mengalami lentur yang cukup besar tanpa runtuh (Ditjen Cipta Karya, 2006). Kelenturan adalah kemampuan untuk mengalami perubahan elastis sehingga struktur akan mempunyai resistensi seismik yang meningkat (Schueller, 1989). Struktur yang fleksibel adalah bagian struktur yang karakteristiknya kekakuan yang kurang dan mempunyai bentuk yang dapat menjawab perubahan beban (Tangaro, dkk., 2005). Prinsip utama bangunan tahan gempa adalah adanya kesatuan dari struktur bangunan, semua unsur bekerja bersama-sama sebagai satu kesatuan, jadi tidak bekerja secara terpisah (Ismail, 2010). Jadi lentur adalah kemampuan untuk mengalami perubahan elastis terhadap perubahan beban dan bersinergi dengan unsur-unsur dari struktur bangunan.

Posisi besi tulangan ringbalk dan besi tulangan sloof terhadap besi tulangan kolom adalah besi tulangan kolom yang masuk ke dalam besi tulangan sloof dan ringbalk. Letak seperti itu karena posisi besi tulangan kolom dalam keadaan berdiri dan kolom diikat oleh sloof. Letak besi tulangan ringbalk terhadap besi tulangan kolom adalah besi tulangan ringbalk masuk ke dalam besi kolom. Letak seperti itu karena besi tulangan ringbalklah yang menahan besi tulangan kolom. Besi behel adalah besi yang sudah terbentuk atau cincin pengikat tulangan besi yang berbentuk empat sudut. Besi behel ada di sloof, kolom, ringbalk, dan balok latei. Besi tulangan perlu lebih besar ukurannya dari pada besi behel agar kekuatan semakin kuat dan besi tulangan adalah tulang punggung dari tiang bangunan, ada di gambar (3). Ukuran besi tulangan yaitu 8", 10", 12", dan 14." Fungsi besi tulangan adalah menjaga beban dari dinding. Di rumah yang bertingkat dua dimensi behelnya adalah lebar behel $20 \mathrm{~cm}$, panjang behel $40-50 \mathrm{~cm}$, dan ditambahkan tulangan besi di tiap tengah- 
tengah besi behel. Besi behel dengan ukuran

lebar $8 \mathrm{~cm}$ dan panjang $12 \mathrm{~cm}$ di tengah-

tengah besi behel bisa diberi besi tulangan

tetapi tidak ekonomis.

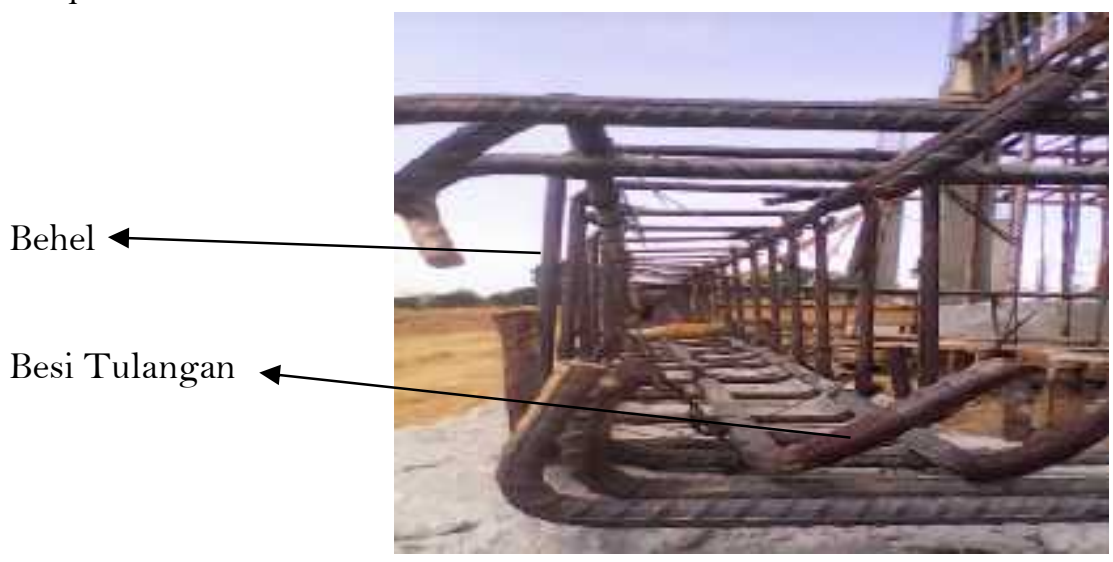

Gambar 3. Besi behel sloof di Sekolah Internasional THR Kendari (Sumber: Hasil dokumentasi pribadi, 2015).

Prinsip pembesian adalah semakin dekat jarak

besi behel semakin kuat pula kekuatan betonnya. Jarak antar besi behel adalah tukang yang menentukan. Ukuran besi behel disesuaikan dengan kemampuan ekonomi penghuni rumah. Jarak antar besi behel pada umumnya adalah $15 \mathrm{~cm}$. Ujung besi behel yang ditekuk (dibengkokkan) berfungsi agar besi tulangan lentur, besi tulangan tetap tidak bergerak ditempatnya, campuran cor saling mengikat dengan besi behel, besi behel tidak mudah terlepas dari beton, dan besi behel saling menyatu dengan beton. Kekuatan pada besi behel ada di tekukkan tersebut. Fungsi angkur yang bagian bawahnya dibengkokkan (ditekuk) adalah agar besi angkur tidak mudah lepas dari campurannya, agar angkur menempel erat di cornya, dan agar tidak mudah tercabut atau tidak mudah bergerak. Kekuatan besi behel yang berbentuk segitiga adalah kurang kuat. Apabila bentuk besi behel segitiga diberi campuran, maka sisi-sisi sudut lancip bagian atasnya kosong atau lebih tebal isi campuran daripada besi tulangan. Campuran cor pada besi behel yang berbentuk segitiga tidak kuat dan mudah retak. Bentuk besi behel segitiga biasanya digunakan di perumahan masyarakat, seperti di kolom, sloof, dan ringbalk karena kuat dan ekonomis. Bentuk behel segitiga kekuatannya sama dengan kekuatan bentuk behel segiempat bila digunakan untuk bangunan rumah sederhana tidak bertingkat. Bentuk behel segitiga bisa digunakan di rumah bertingkat dua, dengan syarat bentuk behel segiempat digunakan pada lantai satu sedangkan bentuk besi behel segitiga digunakan pada lantai dua.

Sloof yang baik bila dicampur (diaduk) proses urut-urutannya adalah 3 ember kerikil, 1 ember semen, dan 2 ember pasir. Perbandingan cor ini berlaku juga untuk rumah dengan jumlah tingkat lantai yang banyak.Campuran yang baik yaitu apabila jumlah kerikilnya lebih banyak daripada jumlah semen dan pasir. Ukuran batu split yang baik untuk digunakan sebagai bahan 
campuran yaitu 2/3 atau 2/4. Apabila pasir terlebih dahulu yang diaduk dengan semen maka batu kerikil/split tidak saling mengikat dengan semen dan pasir. Cor yang sedang diaduk bisa juga proses urut-urutan adukannya adalah semen terlebih dahulu, selanjutnya pasir, dan kerikil. Apabila kerikil dan pasir terlebih dahulu yang diaduk maka proses larutnya semen akan lama.

\section{KESIMPULAN DAN SARAN}

\section{A. Kesimpulan}

Penelitian ini disimpulkan bahwa untuk menemukenali potensi lokal yang

\begin{abstract}
berkaitan dengan pengetahuan tukang bangunan dalam membuat sloof yaitu berprinsip kaku tetapi juga lentur guna merespon bencana alam gempa bumi. Pengetahuan tukang bangunan mengenai bentuk behel segitiga pada sloof mempunyai keunikan sendiri.
\end{abstract}

\section{B. Saran}

Penelitian ini dapat dilanjutkan untuk meneliti pengetahuan tukang bangunan mengenai bentuk behel segitiga pada sloof.

\section{DAFTAR PUSTAKA}

Anonim, 2011. Bagaimana Membangun Rumah Dua Lantai?. Tugas Struktur Utilitas II PSD II Desain Arsitektur - Undip, (Online), (http://scholar.google.co.id, akses tanggal 26 Pebruari 2016). (KP)

Core, S. 2012. Syarat-syarat Struktur Bangunan Gedung Beton Bertulang Lantai Banyak.((Online), http://sawalbank.blogspot.co.id/, akses tanggal 12-03-2016). (PB)

Ditjen Cipta Karya, 2006. Pedoman Teknis Rumah dan Bangunan Gedung Tahan Gempa dilengkapi dengan Metode dan Cara Perbaikan Kerusakan, ((Online), http://scholar.google.co.id, akses tanggal 26 Pebruari 2016). (PB)

Gayatri, C., S., dan Purwanto, L., M., F. 2007. Arsitektur Vernakular Nabire dan Kondisi Nabire Pasca Gempa, ((Online), Dimensi Teknik Arsitektur Vol. 35, No. 1, Juli: 13-22, (http://scholar.google.co.id, akses tanggal 26 Pebruari 2016). (KP)

Harapan, A., dan Triyadi, S. 2008. Kearifan Lokal Rumah Vernakular di Jawa Barat Bagian Selatan Dalam Merespon Gempa, ((Online), Jurnal Sains dan Teknologi EMAS, Vol. 18, No.2, Mei, http://scholar.google.co.id, akses tanggal 26 Pebruari 2016). (KP) 
Hartatik, Setijanti, P., Silas, J., Firmaningtiyas, S., 2012. Eksistensi Rumah Tradisional Padang Dalam Menghadapi Perubahan Iklim dan Tantangan Jaman, ((Online), Simposium Nasional RAPI XI FT UMS, http://scholar.google.co.id, akses tanggal 26 Pebruari 2016). (KP)

Ismail, F., A. 2010. Studi Pengaruh Pemasangan Angkur dari Kolom ke Dinding Bata pada Rumah Sederhana Akibat Beban Gempa. ((Online), Volume 6 No. 1, Februari, ((Online), http://scholar.google.co.id, akses tanggal 26 Pebruari 2016). (PB)

Luthfiah, Amir, F., dan Martini. 2013. Peningkatan Keahlian Tukang dan Buruh Bangunan dalam Membangun Rumah Sederhana Aman Gempa di Kota Palu. Mektek. ((Online), Tahun XV No. 1, Januari, http://scholar.google.co.id, akses tanggal 26 Pebruari 2016). (KP)

Pramitasari, P., H., Iyati, W. 2011. Pengaruh Desain Arsitektur Vernakular Kampung Naga Terhadap Kultur Sosial Masyarakatnya. Prosiding Seminar Nasional The Local Tripod akrab lingkungan, kearifan Lokal, dan Kemandirian. ((Online), Malang 26 Maret, http://scholar.google.co.id, akses tanggal 07 Pebruari 2016). (P)

Raharjo, C., Limanto, S., Suwono, J., S., dan Wuisan, D. 2013. Konstruksi Pondasi Tapak dan Sloof Pada Struktur Bawah Rumah Sederhana Satu Lantai. Konferensi Nasional Teknik Sipil 7 (KoNTekS 7). ((Online), Surakarta, 24-26 Oktober, http://scholar.google.co.id, akses tanggal 26 Pebruari 2016). $(\mathrm{KP})$

Schueller, W. 1989. Struktur Bangunan Bertingkat Tinggi. Cetakan pertama. PT. ERESCO: Bandung. (PB)

Setiawan, B., Widodo, S., Nugroho, M., S., P. 2007. Perancangan Gedung Sekolah Tahan Gempa Di Cabang Muhammadiyah Wesi Klaten, ((Online), Warta, Vol .10, No. 1, Maret: 53-61, http://scholar.google.co.id, akses tanggal 26 Pebruari 2016). (KP)

Soehardjono, A., Dewi, I., C., Dewi, S., M. 2012. Sloof Pracetak Dari Bambu Komposit. Jurnal Rekayasa Sipil, ((Online), Volume 6, No. 1, ((Online), http://scholar.google.co.id, akses tanggal 26 Pebruari 2016). (PB)

Suharjanto, G. 2011. Membandingkan Istilah Arsitektur Tradisonal Versus Arsitektur Tradisional Versus Arsitektur Vernakular: Studi Kasus Bangunan Minangkabau Bali. Architecture Department, Faculty of Engineering, Binus University, ((Online), ComTech Vol.2 No. 2 Desember: 592-602, http://scholar.google.co.id, akses tanggal o7 Pebruari 2016). (P)

Sukamta, D. 2006. Bangunan Tahan Gempa. Artikel ini telah dimuat di harian Kompas, ((Online), Minggu, 11 Juni, http://scholar.google.co.id, akses tanggal 26 Pebruari 2016). (KP) 
Suwono, J., I., Handoyo, F., E., Johan, Sentosa, dan Limanto, Tanpa Tahun. Pekerjaan Sambungan Antara Struktur Pedestal Kolom dan Balok Atas. ((Online), http://scholar.google.co.id, akses tanggal 26 Pebruari 2016). (KP)

Tangaro, D., Somaatmadja, A., S., \& Sukardi, K., 2005. Ilmu Bangunan Struktur Bangunan Rendah. Cetakan Pertama. Penerbit Universitas Indonesia: Jakarta. (PB)

Triyadi, S., Sudrajat, I., Harapan, A. 2009. Kearifan Lokal Pada Bangunan Rumah Vernakular Di Bengkulu Dalam Merespon Gempa Studi Kasus: Rumah Vernakular di Desa Duka Ulu. Seminar Nasional “Kearifan Lokal (Local Wisdom) dalam Perencanaan dan Perancangan Lingkungan Binaan.” PPI Rektorat Universitas Merdeka Malang, 7 Agustus. (P)

Turan, M. 1990. Architecture Vernacular, Paradigsm of Response. USA, Aveburi. (P)

Wijaya, A., Satrio, A., Suryono, A., Seiawan, A., Andrea, H., A. (Tanpa Tahun). Membangun Rumah Dua Lantai (2), ((Online), http://scholar.google.co.id, akses tanggal 26 Pebruari 2016). (KP)

Yustisia, H., Putri, P., Y., Apdeni, R., Sandra, N. 2014. Program Pelatihan kepada Tukang Lokal dalam Rekonstruksi Rumah Pasca Gempa pada Nagari-Nagari di Kabupaten Pasaman. Prosiding Konvensi Nasional Asosiasi Pendidikan Teknologi dan Kejuruan (APTEKINDO) ke-7 FPTK Universitas

Pendidikan Indonesia, Bandung, 13 sd.14 November, ((Online), http://scholar.google.co.id, akses tanggal 26 Pebruari 2016). (KP) 